\title{
OBESITY, INFLAMMATION, VASCULAR REACTIVITY, AND CARDIOCIRCULATORY EVENTS
}

\author{
Joel Faintuch, Lilian M Horie, Vanessa D. Schmidt, Hermes V Barbeiro, Denise F Barbeiro, Francisco G Soriano, Ivan
}

Cecconello

\section{INTRODUCTION}

In the interesting clinical article by Bahia et al, ${ }^{1}$ obese subjects with metabolic syndrome are prospectively compared with lean controls. The addressed question is highly relevant and up-to-date, namely, the relationship between obesity with metabolic syndrome, inflammation, and secretion of adipokines on one hand, and insulin resistance, endothelial function, and vascular reactivity on the other.

They found out that the obese population displayed impaired vascular reactivity, and the 2 measured adipokines, adiponectin and resistin, correlated with 1 vascular reactivity variable each. Inflammation was prominent in this cohort (elevated C-reactive protein/CRP), but comparatively few correlations were assigned to this measurement; just 1 adipokine (resistin) and 1 component of the coagulation cascade, plasminogen activator inhibitor-1 (PAI-1), seemed to be involved.

One may thus speculate that if a link exists between CRP and vascular reactivity, it is an indirect one, via resistin, but as no such result is shown, statistical significance was probably weak or absent. But why should one insist on this detail?

Inflammation, insulin resistance, hyperlipidemia, and hypercoagulability surely bring to mind advanced obesity with metabolic syndrome. Deranged endothelium-dependent and independent vasodilation, along with an increased risk for future cardiocirculatory events, fit very well in this picture. Within this context, the authors feel confident ${ }^{1}$ in attributing much prognostic importance to insulin resistance and to abnormal resistin levels.

It is known, however, that chronic microinflammation, not necessarily associated with insulin resistance and all severe neuroendocrine and metabolic dysfunctions typical of advanced obesity, is a much larger problem involved in a vast array of diseases, from renal failure ${ }^{2}$ to rheumatoid arthritis ${ }^{3}$

Clinical Nutrition Gastroenterology Gastrointestinal Surgery Obesity University Medical School- São Paulo/SP, Brazil

E-mail: faintuch@ipen.br and other autoimmune diseases, ${ }^{4}$ and from chronic obstructive pulmonary disease ${ }^{5}$ and hypopituitary adults ${ }^{6}$ to the elderly in general. ${ }^{7}$ Although inappropriate adipokine expression may not be a prominent feature in these circumstances, cardiovascular death is more probable all the same. Is there a chance that inflammation is a more important culprit?

\section{CLINICAL EXPERIENCE}

In a prospective, placebo-controlled double-blind investigation with 40 morbidly obese subjects, of which 13 were preliminarily evaluated and 24 have completed the protocol, either suffering or not from comorbidities, we were recently able to demonstrate ${ }^{8}$ that CRP, along with serum amyloid A (SAA), another acute phase protein, directly correlated with initial blood glucose, serum lipids, and white blood cell count (Table 1). All of these markers have been associated with increased mortality in different population groups. ${ }^{2-7,9}$

Table 1 - Correlations of C-reative protein and serum amyloid A

\begin{tabular}{lll}
\hline Initial variable & CRP & SAA \\
\hline Blood glucose & & $\mathrm{r}=0.889 * * *$ \\
Total cholesterol & $\mathrm{r}=0.422 * *$ & $\mathrm{r}=0.316 *$ \\
Triglycerides & $\mathrm{r}=0.466 * *$ & $\mathrm{r}=0.871 * * *$ \\
HDL & $\mathrm{r}=-0.375 *$ \\
LDL & $\mathrm{r}=0.502 * *$ & \\
White blood cell count & $\mathrm{r}=0.612 * * *$ & $\mathrm{r}=0.428 * *$ \\
\hline
\end{tabular}

$(*) \mathrm{p}<0.05 ;(* *) \mathrm{p}<0.02 ;(* *) \mathrm{p}<0.01$.

Another point that deserves to be raised is treatment and its impact on the reported aberrations. What are the therapeutic priorities, and which derangement is more amenable to control?

Weight loss is not only imperative, it is theoretically the best prescription. If excess adipose tissue is eliminated, adipokines, including leptin, TNF-alpha, and IL6, will not be overexpressed; therefore, alleviation of in- 
sulin resistance and dyslipidemia will follow, and inflammation and hypercoagulability should regress, all at the same time. Nevertheless, this is easier said than done, and tangible results are not achieved in the short term, but only after substantial time and effort. Furthermore, not all physiological disturbances and comorbidities fully respond to weight reduction. ${ }^{10}$ That is why secondary prevention of cardiovascular events often comprises pharmacologic intervention.

Aiming to get a better insight into the pathophysiology of microinflammation, and to test the hypothesis that nutrients may be safe, inexpensive, and effective, in the same protocol $^{8}$ we introduced flaxseed flour (Farinha de linhaça dourada, Linolive, CISBRA, São Paulo) into the diet. This is a rich source of the vegetable omega-3 fatty acid alphalinolenic acid (ALA) (30 g of supplement/day corresponded to $5 \mathrm{~g}$ of ALA), which is subsequently converted by the liver into eicosapentaenoic acid (EPA), and it is recommended by the American Heart Association for patients without coronary disease. ${ }^{11}$ Within 2 weeks, alleviation of inflammation according to both markers, CRP and SAA, was clearly achieved.

It is worth mentioning that although resistin was not monitored in the study, no change in body weight or tests for glucose, insulin, leptin, or lipids were detected. It is therefore unlikely that insulin resistance influenced any results.

\section{FINAL CONSIDERATIONS}

Reduced long-term morbidity and mortality would be the final proof that one is following the correct pathophysiological path. Experience with ALA is relatively recent, but marine omega-3 fatty acids, which were introduced decades ago, fulfill this requirement. They diminish coronary artery disease, fatal and nonfatal myocardial infarction, sudden cardiac death, and all-cause mortality. ${ }^{11-14}$ Indeed, protection against sudden death after myocardial infarction can be achieved with supplementation for as little as 3 months ${ }^{13}$

Of course, causes of cardiovascular morbidity and mortality can hardly be encompassed by a single trigger or key mechanism. Antiplatelet action, angiotensin inhibition, and lipid lowering may be advantageous, and it is recognized that intake of ALA by itself, besides being anti-inflammatory, shifts the polyunsaturated fatty acid metabolic pathway to EPA, thus favoring the formation of products with a predominant anti-aggregating and vasorelaxing action. ${ }^{14}$ The importance of stabilization of vulnerable atherosclerotic plaques, progression of atherosclerosis, hemostatic activity, and vascular inflammation as well as the potential influence of omega-3 fatty acids have been recently debated as well. ${ }^{15}$

Still, there are reasons to believe that the role of inflammation in cardiovascular morbidity and mortality should be more emphasized, both in obesity/metabolic syndrome and in multiple other illnesses. By the same token, anti-inflammatory maneuvers should be attempted in this setting.

\section{REFERENCES}

1. Bahia L, Aguiar LG, Villela N, Bottino D, Godoy-Matos AF, Geloneze $\mathrm{B}$, et al. Relationship between adipokines, inflammation, and vascular reactivity in lean controls and obese subjects with metabolic syndrome. Clinics 2006;61:433-40.

2. Faintuch J, Morais AAC, Silva MAT, Vidigal EJ, Costa RA, Lyrio DC, et al. Nutritional and inflammatory status of hemodialysis patients. Ren fail. 2006;28:295-311.

3. White D, Fayez S, Doube A Atherogenic lipid profiles in rheumatoid arthritis. N Z Med J. 2006;119:U2125.

4. Abou-Raya A, Abou-Raya S. Inflammation: a pivotal link between autoimmune diseases and atherosclerosis. Autoimmun Rev. 2006;5:331-7.

5. Man SF, Connett JE, Anthonisen NR, Wise RA, Tashkin DP, Sin DD. Creactive protein and mortality in mild to moderate chronic obstructive pulmonary disease. Thorax. 2006;61:849-53.

6. Gomez JM, Sahun M, Vila R, Domenech P, Catalina P, Soler J, et al. Peripheral fibrinolytic markers, soluble adhesion molecules, inflammatory cytokines and endothelial function in hypopituitary adults with growth hormone deficiency. Clin Endocrinol (Oxf). 2006;64:632-9.

7. Jones PH. Dyslipidemia in older adults. Am J Geriatr Cardiol. 2006;15:239-44.

8. Faintuch J, Schmidt VD, Horie LM, Barbeiro HV, Barbeiro DF, Soriano FG, et al. Rev Bras Nutr Clin. 2006; 21:273-8.
9. Coller BS. Leukocytosis and ischemic vascular disease morbidity and mortality: is it time to intervene? Arterioscler Thromb Vasc Biol. 2005;25:658-70.

10. Schernthaner GH, Kopp HP, Kriwanek S, Krzyzanowska K, Satler M, Koppensteiner R, et al. Effect of massive weight loss induced by bariatric surgery on serum levels of interleukin-18 and monocyte-chemoattractantprotein-1 in morbid obesity. Obes Surg. 2006;16:709-15.

11. Kris-Etherton PM, Harris WS, Appel LJ. AHA scientific statement: fish consumption, fish oil, omega-3 fatty acids, and cardiovascular disease. Circulation. 2002;106:2747-57.

12. Oh R. Practical applications of fish oil (n-3 fatty acids) in primary care. J Am Board Fam Pract. 2005;18:28 36.

13. Marchioli R, Barzi F, Bomba E, Chieffo C, Di Gregorio D, Di Mascio $\mathrm{R}$, et al. Early protection against sudden death by $\mathrm{n}-3$ polyunsaturated fatty acids after myocardial infarction: time-course analysis of the results of the Gruppo Italiano per lo Studio della Sopravvivenza nell'Infarto Miocardico (GISSI)-Prevenzione. Circulation. 2002;105:1897-903.

14. Nannicini F, Sofi F, Avanzi G, Abbate R, Gensini GF. Alpha-linolenic acid and cardiovascular diseases omega-3 fatty acids beyond eicosapentaenoic acid and docosahexaenoic acid. Minerva Cardioangiol. 2006;54:431-42.

15. Carpentier YA, Portois L, Malaisse WJ. n-3 fatty acids and the metabolic syndrome. Am J Clin Nutr. 2006;83 (6 suppl): 1499S-1504S. 